\title{
EVALUATION OF LASER AGITATION OF NANOPARTICLE IRRIGANTS ON ROOT CANAL CLEANLINESS: AN IN-VITRO STUDY
}

\author{
Ahmed M. Farag*, Taher M. Islam**, Ahmed M. Farghaly***
}

\begin{abstract}
Objective: The objective of the current study was to evaluate the laser agitation of nanoparticle irrigants on root canal cleanliness. Materials and methods: A total of 60 sounds freshly-extracted maxillary central incisor teeth were collected to be used in this study. The selected roots were divided into two main groups, according to irrigant solution used, thirsty roots each. Each main group was subdivided into three subgroups, according to the agitation of the irrigant solution and the time of agitation used, ten roots each ( $\mathrm{n}=10)$. All roots were prepared using Protaper rotary file system. In group (I) 30 of the selected roots were irrigated with $5 \mathrm{ml} 17 \%$ EDTA solution, 10 roots were not activated, 10 roots were activated by laser for 10 seconds and 10 roots were activated by laser for 20 seconds. All roots were then irrigated with $5 \mathrm{ml} 5.25 \% \mathrm{NaOCl}$ followed by $5 \mathrm{ml}$ saline as a final rinse. In group (II) 30 of the selected roots were irrigated with $5 \mathrm{ml} 0.2 \%$ Chitosan nanoparticle irrigant solution, 10 roots were not activated, 10 roots were activated by laser for 10 seconds, and 10 roots were activated by laser for 20 seconds. Then, these roots were irrigated with $5 \mathrm{ml} 5.25 \% \mathrm{NaOCl}$ followed by $5 \mathrm{ml}$ saline as a final rinse. Specimens were scanned using a scanning electron microscope and statistical analysis was performed using Graph-Pad Instat statistics software. Results: In removal of debris and smear layer the number of open dentinal tubules was higher in group (I) than in group (II) and statistically significant differences were found between both groups in the cervical, middle and apical thirds of the root canals $(\mathrm{P}<.05)$. Conclusions: Laser agitation is an effective technique in debris and smear layer removal when used either with $17 \%$ EDTA or $0.2 \%$ Chitosan nanoparticle irrigant solutions, with better results when used with $17 \%$ EDTA.
\end{abstract}

KEY WORDS: Nano-particle irrigants, Laser agitation, Root canal cleanliness

\section{INTRODUCTION}

Irrigation is an essential part of the root canal treatment that allows cleaning of the rootcanal system beyond that might be achieved by instrumentation alone $^{(1)}$. Adequate irrigation of root canals requires an effective irrigant that is non-toxic, non-irritant, and has antibacterial activity with an ability to dissolve organic and inorganic tissues. Efficient delivery systems can bring irrigating solutions into direct contact with the entire canal wall surfaces, particularly for the apical portions of narrow root canals ${ }^{(2,3)}$. During cleaning and shaping procedures, a superficial amorphous layer of tissue remnants, organic and inorganic materials, and bacteria with their byproducts accumulate on the canal walls; this is called the smear layer. The presence of the smear layer attached to the canal wall impairs irrigants, medications, and endodontic sealers from accessing dentinal tubules. Although the removal of smear layer is a controversial issue, its removal is very important because if not removed it will prevent the adhesion of the sealer to the canal wall and serve as a substrate for bacterial growth ${ }^{(4)}$. There is no one unique irrigant that meet all requirements so, in contemporary endodontic practice dual irrigants are used such as sodium hypochlorite $(\mathrm{NaOCl})$, which can remove the organic components of the smear layer, and chelators such as (EDTA) have been used to remove the inorganic components ${ }^{(5,6)}$.

\footnotetext{
* Department of Endodontics, Faculty of Dental Medicine, Boys, Cairo, Al Azhar University.

** Professor of Endodontics, Faculty of Dental Medicine, Boys, Cairo, Al-Azhar University.

*** Associate Professor of Endodontics, Faculty of Dental Medicine, Boys, Cairo, Al-Azhar University.
} 
Recently, researchers have focused on developing new irrigants and establishing alternative irrigation protocols for better cleanliness of root canals $^{(7-9)}$. Manufacturers claim that laser is a powerful machine-assisted irrigation system. However, up till now, no irrigant system is recommended to be used. Recently, irrigant solutions incorporating nanoparticles are used ${ }^{(10,11)}$. It is claimed that chitosan nanoparticles irrigant solution can be used in cleanliness of the root canals because it has efficient chelating and antimicrobial effect ${ }^{(12-14)}$. With this regard, the present study was directed to evaluate the laser agitation of nanoparticle irrigants on the root canal cleanliness.

\section{MATERIALS AND METHODS}

Laser irradiation was applied by using the equipment of SIROLaser ${ }^{\circledR}$ Advance, which is a $980-\mathrm{nm}$ wavelength gallium-aluminum-arsenide diode laser, after placement of the chelating agent. This system is equipped with a $20-\mathrm{W}$ power source. The laser beam power emitted through $200-\mu \mathrm{m}$ sized flexible fiber-optic tip and actual energy density of the parallel fiber-optic tip was $18 \mathrm{~J} / \mathrm{cm}^{2}$. The standardized settings were $18 \mathrm{~J} /$ pulse, $100 \mathrm{~Hz}$, average power 1.8 $\mathrm{W}$, in pulsed mode, time is 10 seconds and the duty cycle is $90 \%$. During irradiation, the laser tip was introduced 2-3 mm short of the working length and was withdrawn gently from the apical region to the coronal region with a circular movement.

Sixty humans freshly extracted straight permanent maxillary central incisor teeth with type I root canal morphology and fully formed root apices were collected from the outpatient clinic of the Oral Surgery Department, Faculty of Dental Medicine, Al-Azhar University in Cairo, Egypt, to be used in this study. Selected teeth were radiographically examined to exclude any roots that had abnormalities such as root fractures, pulp stones or internal resorption. These teeth were decapitated using carborundum disk mounted in a high speed hand piece under water coolant to adjust the roots to be $16 \mathrm{~mm}$ in length from the anatomical apex.
Selected roots were stored in normal saline at room temperature till the time of testing.

Prior to preparation the working length was estimated by placing a size $\# 15 \mathrm{~K}$ file into the root canal until it was visible at the apical foramen and subtracting $1 \mathrm{~mm}$ from that length. Then, root canals were instrumented using the Protaper Universal rotary system in a sequence SX, S1, S2, F1, F2,F3 and $\mathrm{F} 4$ as a master apical file. Root canal irrigation was done after each file using $2 \mathrm{ml} \mathrm{NaOCl}$ (5.25\%). The delivery of all irrigants in this study was done by Max-I-Probe endodontic irrigating needle (with 30 gauge and $25 \mathrm{~mm}$ in length), which was attatched to conventional disposable syringe within $1 \mathrm{~mm}$ of the working length. Root canals were irrigated with $5 \mathrm{ml}$ saline then dried with paper point to receive the final irrigants.

The roots were divided according to the type of final irrigant into two main groups (Chitosan nanoparticle solution $0.2 \%$ group $(\mathrm{pH}=3.2)$ ( $\mathrm{C}$ group $)$ \& EDTA solution $17 \%$ group (E group) $(\mathrm{pH}=7.5))$ Each group was subdivided into three subgroups according to the activation by laser and the time of activation (10 roots in each subgroup, $n=10$ ); the no activation subgroup (control subgroup) had ten roots irrigated with $5 \mathrm{ml}$ of the chelating agent for 3 minutes then irrigated with $5 \mathrm{ml} 5.25 \% \mathrm{NaOCl}$ then finally with $5 \mathrm{ml}$ saline. The laser-activated subgroup for 10 seconds (+10subgroup) had ten roots irrigated with $1 \mathrm{ml}$ of the chelating agent and activated by laser for 10 seconds then irrigated with $4 \mathrm{ml}$ of the same chelating agent for 170 seconds then irrigated with $5 \mathrm{ml} 5.25 \% \mathrm{NaOCl}$ then finally with $5 \mathrm{ml}$ saline. The laser-activated subgroup for 20 seconds (+20subgroup) had ten roots irrigated with $2 \mathrm{ml}$ of the chelating agent and activated by laser for 20 seconds $(1 \mathrm{ml}$ of the chelating agent activated by laser for 10 seconds and this process repeated two times, then irrigated with $3 \mathrm{ml}$ of the same chelating agent for 160 seconds then irrigated with $5 \mathrm{ml} 5.25 \%$ $\mathrm{NaOCl}$ then finally with $5 \mathrm{ml}$ saline).

Two incomplete longitudinal grooves were prepared on the mesial and distal surfaces of each root 
specimen using a metal diamond disk $(0.6 \mathrm{~mm}$ thick) mounted in a straight low speed handpiece with water spray. The grooves were not deep enough to enter the canals then the root canal was dried with paper point\# 40. Gutta Percha point \# 40 was inserted into the root canal to prevent debris contamination during the splitting then vertical splitting was done with a size 15 blade into two halves. The half containing the most visible part of tha apex and best represented the total canal length was secured and coded. Coded root halves were mounted on an aluminum stub and coated with gold-palladium by gold sputter coater. Specimens were examined at the center of coronal, middle and apical regions at $500 \mathrm{X}$ magnification by a scanning electron microscope for debris evaluation. This was followed by examining the same specimen at $3000 \mathrm{X}$ for the smear layer evaluation. Images obtained were analyzed using scoring systems that were described by Peters and Barbakow ${ }^{(15)}$.

Statistical analysis was performed using GraphPad Instat statistics software for Windows ${ }^{\circledR}$.

\section{RESULTS}

Data analysis was performed in several steps. Initially, frequent distribution of score rate (\%) for each group and subgroups results was done. Chisquare test of significance was done for comparing variables (main group, subgroups and regions of scanning) affecting score rate (\%) values to detect interaction between variables of significant effect. $P$ values $\leq 0.05$ are considered to be statistically significant in all tests. The amount of smear layer and debris remaining in the canal was quantified using the NIH Image J V1.56 software program.

Comparison between amounts of debris and smear layer scores (\%) for each main group as a function of subgroups and root regions. Frequent distribution for amounts of debris and smear layer scores (\%) at cut dentin surfaces for each main group as function of subgroups and root regions summarized in (Table 1) and graphically represented in (Figure 1).

TABLE (1) Frequent distribution for amounts of debris and smear layer scores (\%) at cut dentin surfaces for each main group as function of subgroups at each radicular region.

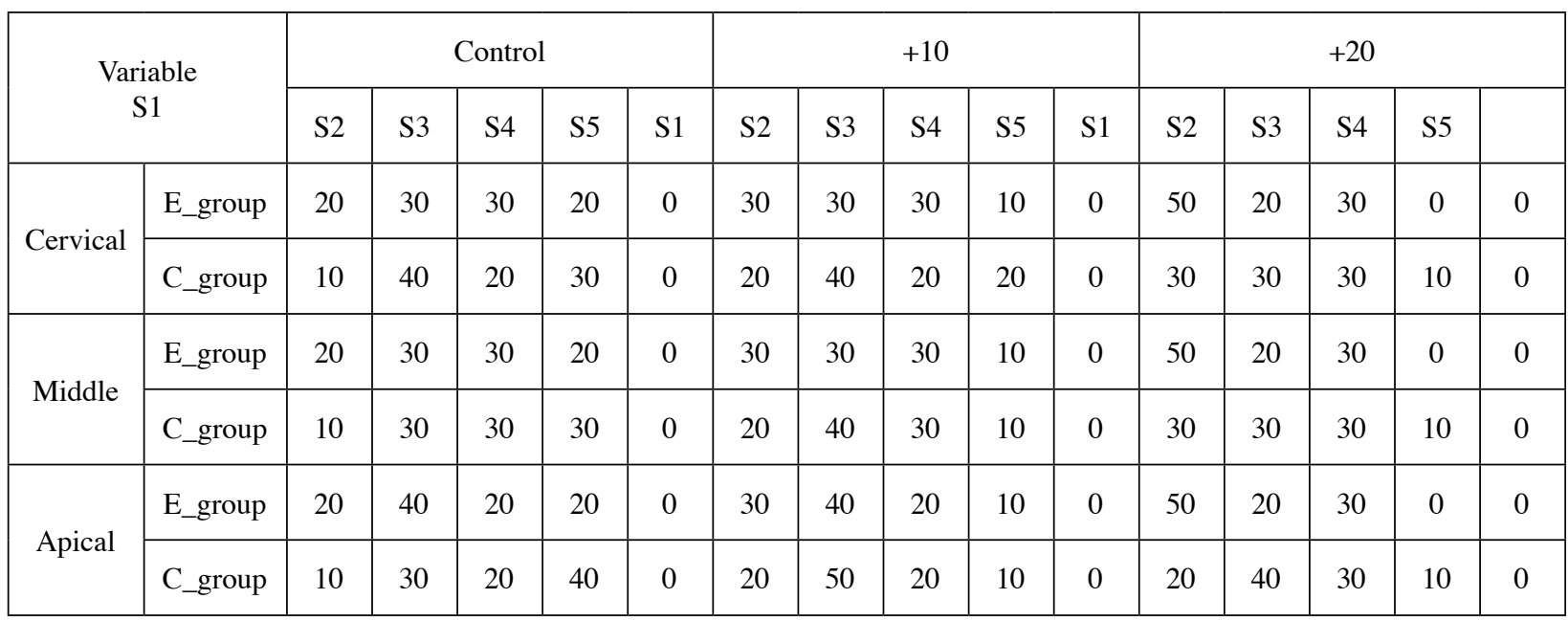




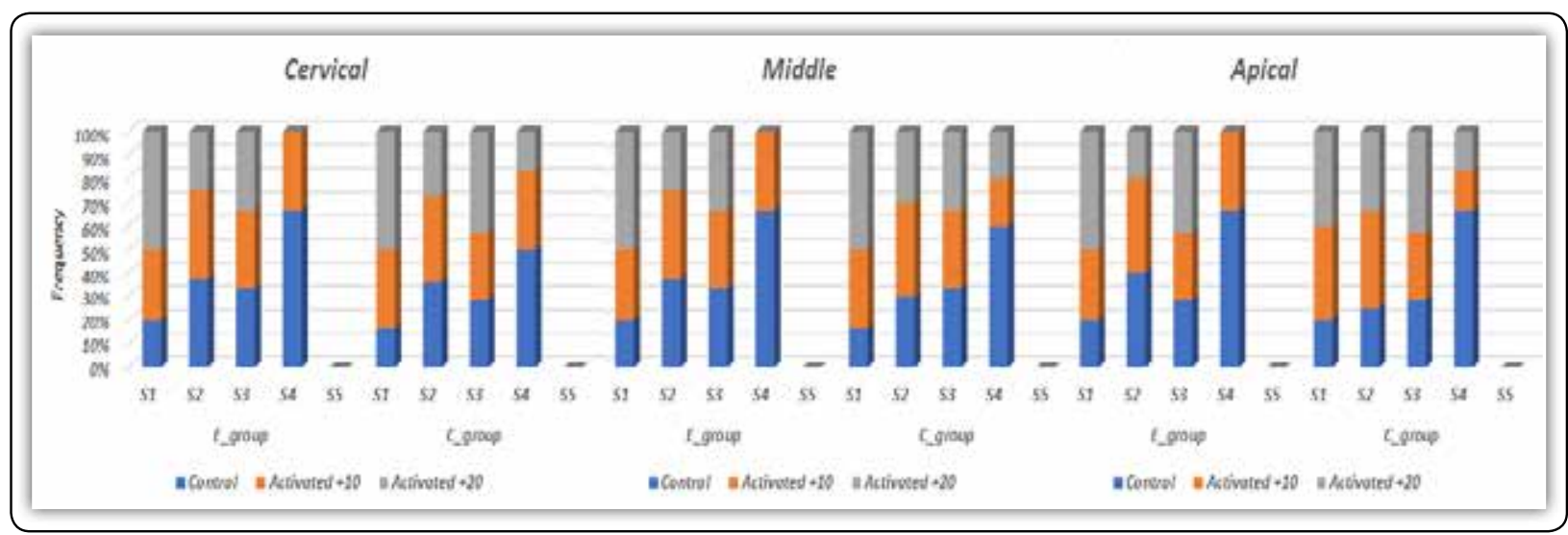

FIG (1) A stacked column chart of frequent distribution of different scores for amounts of debris and smear layer attributed to different regions for each main group as function of subgroups.

Comparisons between both groups, for each subgroup according to the region of scanning, were made. At the cervical region, there was a statistically significant difference between all subgroups in the scores of amounts of debris and smear layer between both groups. At middle region, there was not statistically significant difference in the scores of amounts of debris and smear layer between the Control and 10seconds activation subgroups with both groups, while there was a statistically significant difference in the scores of amounts of debris and smear layer in the 20 seconds activation subgroup between both groups. At apical region, there was a statistically significant difference in the scores of amounts of debris and smear layer in the Control and 20 seconds activation subgroups between both groups, while in the 10 seconds activation subgroup there was not statistically significant difference in the scores of amounts of debris and smear layer between both groups.

Comparisons between the three subgroups within each group at all regions showed that in the EDTA and Chitosan nanoparticles groups the difference in the scores of amounts of debris and smear layer between the three subgroups was statistically significant.

\section{DISCUSSION}

In endodontic treatment, cleaning is the removal of all contents of the pulp space system before and during shaping. Successful cleaning entails the use of instruments to physically remove contents, irrigating systems to flush loosened materials away, and chemicals to dissolve contents from inaccessible regions ${ }^{(16)}$. The smear layer is formed during instrumentation, consisting of not only dentin but also necrotic and viable tissue, including remnants of odontoblastic processes, pulp tissue and bacteria. This smear layer plays an important role in the lateral sealing of the root canal by acting as an intermediate physical barrier that may interfere with adhesion and penetration of the root canal sealer into the dentinal tubules so the smear layer removal is essential ${ }^{(17)}$

This study compared the effect of laser agitation of different irrigation solutions $(0.2 \%$ Chitosan nanoparticles solution and 17\% EDTA solution) as final irrigants on the debris and the smear layer removal after root canal preparation with rotary Protaper files. EDTA $17 \%$ was used in this study as it is a nontoxic chelating agent and it has the capacity to dissolve inorganic components of smear layer ${ }^{(18)}$. Chitosan nanoparticles irrigant solution $0.2 \%$ was used in this study as Chitosan is the 
most abundant substance in nature after cellulose making its use ecologically interesting ${ }^{(19)}$. This polysaccharide has properties of biocompatibility, biodegradability, bioadhesion and antimicrobial activity and possesses high chelating capacity for various metal ions including Calcium, Zinc, Cobalt, Iron, Magnesium, and Cupper ions in acid conditions because it has large numbers of hydroxyl and free amino groups ${ }^{(20)}$. Laser was used in the activation of irrigants because it produces a cavitation effect, which generates vapor-containing bubbles, initiating shock waves, which in turn detach the smear layer and disrupt bacterial biofilms. The fiber tip of SIROLaser ${ }^{\circledR}$ Advance was moved inside the root canal in a circular movement to allow minimizing of overheating of the root canal dentin ${ }^{(21)}$ and kept 2-3 $\mathrm{mm}$ away from the anatomic apex in order to avoid irrigant extrusion from the apex ${ }^{(22)}$, which due to the rapid formation of vapor bubbles, may cause damage to the apical constriction and extrusion of irrigating solution beyond the root apex ${ }^{(23)}$.

Statistical analysis of data showed that when using $17 \%$ EDTA as an irrigating solution at apical, middle and coronal segments of root canal more smear layer and debris removal can be achieved than when Chitosan irrigant solution was used. This result may be due to the fact that EDTA has four active $(\mathrm{OH})$ groups which may increase its chelating effect or its property of continuous demineralization action until all calcium ions have been bounded, forming stable complexes. Another possible cause is its ability to reduce the mineral and non-collagenous protein components of the dentin, since it can remove not only calcium ions but also water soluble non-collagenous protein. These results were in agreement with Silva et al. ${ }^{(24)}$ who found that the highest removed calcium ion concentration after irrigation was observed with $15 \%$ EDTA when compared with $0.2 \%$ chitosan and that indicate more chelating ability.

Moreover, statistical analysis of data showed that laser agitation of irrigants used stimulate more removal of smear layer and debris. This may be due to the production of a cavitation effect which in turn may detaches the smear layer and help flushing out debris. These results were in agreement with George et al. ${ }^{(25)}$ who examined the capacity of lasers to activate the irrigating liquids inside the root canal to increase its action and reported that the laser activation of irrigants provided better cleaning and removal of the smear layer from the dentinal surfaces.

Time of agitation of irrigants was also another important factor in the cleaning process. Increased time of agitation has led to an increase in the removal of smear layer and debris. Agitation of irrigants used for 20 seconds was shown to be more effective in cleaning the root canal system, due to the increase in removal of the smear layer and debris at this time of agitation. These results were in agreement with Hakan et al. ${ }^{(26)}$ who evaluated the efficacy of agitation of 15\% EDTA with an 808-nm diode laser on removal of the smear layer for 10, 20, 30 , and 40 seconds and concluded that the agitation of $15 \%$ EDTA with an 808-nm diode laser for 20 seconds was more effective in removing the smear layer in the apical thirds of root canals.

\section{CONCLUSIONS}

Within the limitations of this study it can be concluded that, laser agitations was an effective technique in debris and smear layer removal when used either with $17 \%$ EDTA or $0.2 \%$ Chitosan nanoparticle irrigant solutions, and can provide more cleaning when used with $17 \%$ EDTA solution.

\section{REFERENCES}

1. Haapasalo M, Endal U, Zandi H and Coil J. Eradication of endodontic infection by instrumentation and irrigation solutions. Endodontic Topics 2005; 10: 77-102.

2. Dunavant T, Regan J, Glickman G, Solomon E and Honeyman A. Comparative evaluation of endodontic irrigants against Enterococcus faecalis biofilms. J Endod 2006; 527:31-2. 
3. Hsieh Y, Gau C, Kung S and Shen E. Dynamic recording of irrigating fluid distribution in root canals using thermal image analysis. Int Endod J 2007; 40:11-7.

4. Clark H, Drake D, Walton R, Rivera E and Guthmiller J. Bacterial penetration through canals of endodontically treated teeth in the presence or absence of the smear layer. J Dent 2003; 31:275-81.

5. Zehnder M. The root canal irrigants role in removal of the inorganic components of the smear layer. J Endod 2006; 32:389-98.

6. Kamburis J, Barker T, Barfield R and Eleazer P. Removal of organic debris from bovine dentin shavings. J Endod 2003; 29:559-61.

7. Mancini M, Cerroni L, Iorio L, Armellin E, Conte G and Cianconi L. Smear layer removal and canal cleanliness using different irrigation systems (EndoActivator, Endovac, and passive ultrasonic irrigation): field emission scanning electron microscopic evaluation in an in vitro study. $\mathrm{J}$ Endod 2013; 39:1456-60.

8. Bolles J, He J, Svoboda K, Schneiderman E and Glickman G. Comparison of Vibringe, EndoActivator, and needle irrigation on sealer penetration in extracted human teeth. $\mathbf{J}$ Endod 2013; 39:708-11.

9. Ordinola-Zapata R, Bramante C, Aprecio R, Handysides $\mathrm{R}$ and Jaramillo D. Biofilm removal by $6 \%$ sodium hypochlorite activated by different irrigation techniques. Int Endod J 2014; 47:659-66.

10. Nielsen B, Baumgartner J. Comparison of the Endovac system to needle irrigation of root canals. J Endod 2007; 33:611-5.

11. Munley P, Goodell G, Waltimo T and Ribbin J. A comparison of passive ultrasonic debridement between the fluted and non-fluted instruments in root canals. J Endod 2007; 33:578-80.

12. Anousheh P, Dennis G, Suja S and Anil K. Bioactive Chitosan Nanoparticles and Photodynamic Therapy Inhibit Collagen Degradation: In-Vitro Study. J Endod 2014 ;40: 703-709.

13. Aldo D, Anil K, Annie S and Clovis M. Antibacterial Properties Associated with Chitosan Nanoparticle Treatment on Root Dentin and 2 Types of Endodontic Sealers. J Endod 2015; 41:1353-1358.

14. Annie S, Martha C, and Anil K. Photoactivated Polycationic Bioactive Chitosan Nanoparticles Inactivate Bacte- rial Endotoxins. Annie S, Martha C, and Anil K. J Endod 2015;41:686-691.

15. Peters O, Barbakow F. Effects of irrigation on debris and smear layer on canal walls prepared by two rotary techniques: a scanning electron microscopic study. J Endod 2000; 26: 6-10

16. Guerisoli D, Marchesan M, Walmsley P and Pecora J. Evaluation of smear layer removal by EDTAC and $(\mathrm{NaOCl})$ with ultrasonic agitation. Int Endod J 2002; 5: 418-421.

17. Sen B, Wesselink $P$ and Turkun $M$. The smear layer: a phenomenon in root canal therapy. Int Endod J 1995; 28:141-8.

18. Hakan A, Leyla B, Ertugrul K, Huseyin S, Muhammet S and Bertan K. Effect of agitation of EDTA with 808-nanometer diode laser on removal of smear layer. J Endod 2013; 39:1589-92.

19. Shi Z, Neoh KG, Kang ET and Wang W. Antibacterial and mechanical properties of bone cement impregnated with chitosan nanoparticles. Biomat 2006; 27:2440-9.

20. Akncbay H, Senel S and Ay ZY. Application of chitosan gel in the treatment of chronic periodontitis. J Biomed Mater Res B Appl Biomater 2007; 80:290-6.

21. Camargo SE, Valera MC, Camargo CH, Fonseca MB and Menezes MM. Effects of Nd: YAG laser irradiation on root canal dentin wall: a scanning electron microscopic study. Photomed Laser Surg 2005; 23:399-404.

22. George R and Walsh LJ. Apical extrusion of root canal irrigants when using Er: YAG and Er, Cr: YSGG lasers with optical fibers: an in vitro dye study. J Endod 2008; 34:706-8.

23. Matsuoka E, Jayawardena JA and Matsumoto K. A morphological study on root canal preparation using erbium, chromium: YSGG laser. J Oral Laser Appl 2005; 5:17-22.

24. Silva PV, Guedes DFC, Nakad FV, Pécora JD and CruzFilho AM. Chitosan: a new solution for removal of smear layer after root canal instrumentation. Int Endod J2013; 46, 332-338.

25. George R, Meyers IA and Walsh LJ. Laser activation of endodontic irrigants with improved conical laser fiber tips for removing smear layer in the apical third of the root canal. J Endod 2008; 34:1524-7.

26. Hakan A, Leyla B, Ertugrul K, Huseyin S, Muhammet S and Bertan K. Effect of agitation of EDTA with 808-nanometer diode laser on removal of smear layer. J Endod 2013; 39:1589-92. 